\title{
Histórias contadas: análise de uma experiência entre os Anishinabe
}

Telling history: analysis of an experience among the Anishinabe

\author{
Juliana Braz Dias* \\ *Universidade de Brasília - Brasília, DF, Brasil \\ jbrazdias@hotmail.com \\ https://orcid.org/0000-0003-0316-971X
}




\title{
Resumo
}

Neste trabalho, procuro primeiramente discutir a necessidade, cada vez mais evidente, de tomar os museus como objeto de investigação antropológica. Incentivo uma análise dos museus capaz de perceber nos mesmos dois tipos de procedimentos tradicionalmente abordados pela antropologia: a classificação e a atribuição de valor. Os museus são aqui tomados como narrativas construídas sobre realidades diversas. Em um segundo momento, parto para a aplicação dessas ideias no estudo de um caso particular: o Ziibiwing Center, um centro cultural construído pelos índios Anishinabe, na cidade de Mount Pleasant (Michigan, Estados Unidos da América). A descrição e a análise da exposição de longa duração desse centro cultural vêm revelar uma narrativa em que o tempo histórico e o tempo mítico se entrelaçam. A experiência do presente é organizada em termos do passado e direcionada para o futuro.

Palavras-chave: museu indígena; Anishinabe; mito; história.

\begin{abstract}
In this paper, I discuss, at first, the increasingly evident need to address museums as an anthropological research object. I encourage an analysis of museums that is capable of perceiving in them two types of procedures traditionally studied by anthropologists: classification and attribution of value. Museums are taken as constructed narratives about diverse realities. In the second part of the paper, I apply these ideas in the study of a particular case: the Ziibiwing Center, a cultural center built by Anishinabe Indians, in Mount Pleasant (Michigan, United States of America). The description and analysis of the permanent exhibition of this cultural center reveal a narrative in which historical time and mythical time are intertwined. The experience of the present is organized according to the past and directed towards the future.
\end{abstract}

Keywords: indigenous museum; Anishinabe; myth; history. 


\section{Introdução}

No contexto das crescentes discussões sobre a temática do patrimônio cultural, os museus têm sido vivenciados e explorados de maneiras diversas. Tradicionalmente, os museus foram associados, por um lado, a experiências de lazer cultural (em especial, no que toca às classes privilegiadas) e, por outro lado, a práticas de colecionamento, investigação e realização de exposições por parte de pesquisadores de diversos campos do saber. Nas últimas décadas, os museus têm-se tornado também, eles próprios, rico objeto de investigação antropológica. Como parte de uma tendência autorreflexiva da antropologia, realiza-se assim uma passagem das pesquisas em museus para as pesquisas sobre museus. ${ }^{1}$

As reflexões aqui propostas têm paralelo com essa transformação no seio da antropologia, a partir de uma experiência particular. Nascem de um simples passeio por um museu indígena ou, como discutirei adiante, um "centro cultural". Circunstâncias pessoais levaram-me à cidade norte-americana de Mount Pleasant (Michigan), na região dos Grandes Lagos, onde me deparei com um museu organizado pelo grupo indígena Saginaw Chippewa. Mas a experiência original de lazer ganhou nova dimensão sob o olhar de uma antropóloga. Neste texto, de caráter ensaístico, busco dar sentido à experiência museológica de indígenas de Michigan, em sua particularidade e nas questões mais gerais que suscita.

Procuro enfatizar a necessidade, cada vez mais evidente, de tomar os museus como objeto de análise antropológica. Particularmente, insisto na potencialidade de estudos capazes de perceber nos museus dois tipos de procedimentos tradicionalmente abordados pela antropologia: a classificação e a atribuição de valor. Por meio desses procedimentos básicos, constrói-se determinada ordenação de algum aspecto da realidade, em narrativas articuladas e transmitidas a públicos diversos. Os museus são aqui tomados como construções discursivas.

Em um segundo momento, parto para a aplicação dessas ideias por meio de reflexões sobre o caso particular do museu dos índios Anishinabe, na cidade

1 A propósito dessa discussão, conferir Lima Filho, Eckert e Beltrão (2007). 
de Mount Pleasant (Michigan, Estados Unidos da América), com sua peculiar estratégia narrativa. A descrição e a análise da exposição de longa duração do museu vêm revelar uma narrativa sobre esse grupo, em que o tempo histórico e o tempo mítico se entrelaçam almejando o reposicionamento dos Anishinabe no cenário sociopolítico local e nacional.

\section{Antropologia, cultura material e museus}

A cultura material de grupos diversos sempre despertou a atenção dos antropólogos, que buscaram, por meio desse aspecto tangível da realidade sociocultural, descobrir e compreender outras dimensões da vida em sociedade. Inicialmente, ainda nos primórdios da antropologia, a cultura material era tomada sobretudo como um índice do desenvolvimento das sociedades, permitindo a construção, pelos pesquisadores, de elaborados modelos explicativos de cunho evolucionista. ${ }^{2}$ A realização de inventários, seguida de procedimentos de classificação (tanto dos objetos levantados quanto das sociedades às quais os mesmos se vinculavam), era prática comum, fundamentando grandes construtos teóricos. Classificados e hierarquizados, os objetos de cultura material pesquisados diziam mais sobre a visão de mundo desses investigadores, baseada em uma explicação da diversidade humana a partir da ideia de progresso, do que sobre as populações onde tinham origem tais objetos.

Posteriormente, novo interesse foi construído em torno da cultura material, com a atenção dos antropólogos direcionada agora aos significados agregados a essas produções culturais. O novo esforço interpretativo parte de uma constatação simples e fundamental: um mero objeto pode adquirir sentidos os mais diversos a depender do contexto onde se encontra inserido. Por trás dessa ideia está um conceito de cultura mais plural e uma concepção do ofício do antropólogo menos inclinada aos grandes esquemas teóricos e mais aberta ao estudo do particular. Deriva-se daí a certeza de que desvendar os significados de qualquer elemento de cultura material, interpretando-os, é ir além da superficialidade da observação, da construção de inventários e da classificação, exigindo

2 Ver, por exemplo, Morgan (1877). 
um movimento radical em direção ao recôndito do domínio cultural de uma sociedade particular. Como qualquer outro aspecto da cultura, um objeto de cultura material só pode ser devidamente compreendido quando analisado em relação ao contexto sociocultural ao qual pertence. E basta, para ilustrar essa ideia, um exemplo clássico. Um simples colar de conchas vermelhas pode abrir ampla discussão sobre os campos econômico, político, simbólico e cosmológico na sociedade trobriandesa - sendo, só assim, devidamente compreendido (Malinowski, 1976).

O cuidado especial dedicado ao contexto onde se insere determinado objeto tem outros desdobramentos. Pelas mais diversas razões, os objetos também circulam. Não raro, eles ganham novos espaços e, nesse movimento, novos significados. Que sentido pode ter uma máscara fabricada pelos Mano, na Libéria, comercializada em um mercado do Senegal e comprada por um turista alemão em viagem pela costa oeste africana? Certamente, não mais o sentido original daquela peça, agregando agora novas ideias, valores e práticas. São esses processos de ressignificação que vêm ganhando terreno em análises antropológicas que procuram dar conta do caráter singular de cada sociedade, mas igualmente da dinâmica cultural e das histórias de contatos e trocas que se refletem na vida social dos objetos. ${ }^{3}$

Dessa discussão, os museus não podem ficar de fora. Como um locus que abriga objetos os mais diversos, advindos dos mais variados contextos, os museus configuram-se como cenários onde diferentes atores participam desse processo de criação e recriação de novos significados. Da fabricação de um objeto em uma sociedade indígena à sua exposição na prateleira de um museu citadino, um longo caminho é percorrido. E são de grande importância os estudos que busquem compreender o(s) sentido(s) adquirido(s) pelos objetos coletados, selecionados, colecionados, preservados e exibidos em museus. ${ }^{4}$

É notório o interesse, no debate acadêmico recente, por uma "antropologia dos museus", que cresce em legitimidade e importância. A questão acompanha de perto outra, que lhe é logicamente anterior, sobre a desnaturalização das ideias de "preservação", "patrimônio" e "monumentos", sejam eles artísticos ou

3 A título de exemplo, ver Kopytoff (1986).

4 Ver, por exemplo, Price (2000). 
históricos. Trata-se de uma tarefa nada fácil num campo que, no Ocidente, está profundamente articulado a importantes construções ideológicas, principalmente de caráter nacionalista.

Os museus, da maneira como os conhecemos, são resultado de um momento histórico muito preciso. Apesar de admitirmos que as práticas de colecionamento não foram inventadas pelas sociedades modernas, podendo mesmo ser consideradas uma prática universal (Clifford, 1994; Gonçalves, 2003a), o modelo de museu hoje preponderante (e o campo semântico a ele agregado) surgiu em meio aos elaborados processos de formação dos Estados nacionais no oeste europeu.

Remetem a finais do século XVIII e início do século XIX os primeiros instrumentos significativos de preservação voltados para objetos de arte e edificações, seja por meio da construção de museus ou da organização de inventários. Esses esforços traduziam, em última instância, o desejo maior de formação dos "patrimônios nacionais", capazes de dar concretude e sustentação à ideia de uma nação unificada e indivisível. O "espírito do povo", usando aqui a expressão consagrada por Johann Gottfried Herder, tornava-se evidente nas obras preservadas, colecionadas e exibidas cuidadosamente nos museus. Organizados por meio de políticas estatais específicas, os museus uniam grupos heterogêneos em torno de uma ideia de pertencimento única, um projeto único de nação e de memória nacional, representado pelas coleções. ${ }^{5}$

A discussão sobre a artificialidade dos museus ganha novo vigor quando nos detemos aos processos de seleção e classificação a eles inerentes. Em um museu-padrão, organizar uma exposição significa, antes de tudo, escolher o material a ser exposto e dispor as obras espacialmente, seguindo uma ordem determinada. Em toda sociedade, em qualquer atividade de ordenação, a classificação e a hierarquização são procedimentos fundamentais - trata-se de uma necessidade humana vital, como já alertavam Durkheim e Mauss (1981). E não poderia ser diferente com os museus. A seleção do material a ser exposto (realizada por agentes específicos, com poder legítimo para tal), sua classificação e mesmo nominação, através das etiquetas que usualmente

5 Uma discussão mais aprofundada sobre essa temática pode ser encontrada em Gonçalves (1996) e Sant'Anna (2003). 
o acompanham, junto com sua ordenação no espaço, formam etapas de um processo de construção de uma narrativa. Cria-se, através de um ordenamento específico, um sentido novo. Não se trata mais de uma borduna panará, uma gravata xavante, um parico bororo e um adorno labial karajá, em seus contextos de origem, nem mesmo cada um deles isolados. São todos, juntos, articulados em um discurso que algo quer transmitir ao visitante da exposição.

O museu pode ser percebido, assim, como um texto, a ser decodificado e interpretado pelo público. A organização de uma exposição pressupõe a atribuição de valor às peças expostas. Independentemente do contexto de produção dessas obras, seus usos e os sentidos que originalmente agregavam, elas ganharão novos significados com a experiência do museu - significados esses continuamente reelaborados por cada indivíduo que visita a exposição. São histórias contadas, apreciadas e sempre reinterpretadas.

Reforço, neste ponto, um diferencial da antropologia. Trata-se de um campo do saber que tem participado do processo de construção dessas narrativas, como uma disciplina atuante desde suas origens na prática dos museus, e que, simultaneamente, tem-se dedicado à reflexão sobre essa mesma prática e suas consequências. Os antropólogos são agentes com poder legítimo para valorizar objetos e construir ícones de culturas diversas. Mas podem e devem, igualmente, refletir sobre os mecanismos que estão por trás dessas escolhas.

\section{Novos museus}

A contemporaneidade tem trazido com ela, entre tantas outras mudanças, a transformação do conceito de museu. No Brasil e em muitos outros países, a ideia de sociedades nacionais pluriétnicas vem substituindo o antigo Estado unificado, construído por um viés homogeneizante. Assim, as grandes homogeneizações vão dando lugar às noções de fragmentação e pluralidade, com reflexos evidentes nos novos projetos preservacionistas. Novas formas de concepção do patrimônio geram debates inovadores, nos quais a cultura ganha nova cara: desmaterializada, dinâmica e plural. E, com tais transformações, os antigos museus nacionais vão cedendo espaço, paulatinamente, a novas experiências museológicas. 
A chamada "nova museologia" é produto de um processo de descolonização museológica. Argumentos elaborados pela antropologia do colonialismo e pelas críticas pós-modernas apontam os antigos museus etnográficos como uma tecnologia de dominação. ${ }^{6}$ Tais críticas têm estimulado, em contrapartida, o exercício de "trabalhos colaborativos" (ou curadorias compartilhadas). Estes, realizados por meio da participação conjunta de profissionais especializados nos museus e membros de sociedades indígenas, vêm impulsionar a reflexão sobre a autoria nas práticas museais - tanto no Brasil quanto no exterior (Lima Filho; Athias, 2016; Roca, 2015). As exposições colaborativas seriam uma maneira de distanciar-se dos vícios do passado, apostando nos benefícios de uma metodologia dialógica, com uma troca benéfica entre as partes envolvidas.?

Seguindo a tendência de sua vocação original, os museus passam por um processo de fortalecimento do seu papel como legitimadores de identidades - mas agora não exclusivamente identidades nacionais. Os projetos preservacionistas estão na ordem do dia. Cada cidade busca ter seu museu, e cada categoria social e grupo étnico, seu próprio patrimônio preservado.

Os grupos étnicos, em especial, revelam um desejo crescente de serem sujeitos de sua própria experiência museológica. Surgem propostas que articulam a ideia de patrimônio à de autonomia e liberdade. Aos museus etnográficos, somam-se os museus indígenas - numa passagem das coleções etnográficas sobre o "outro" a exposições sobre "nós". E é com base em uma luta de caráter democratizante que variados atores insistem em que os museus devem representar os diversos grupos étnicos existentes (Gonçalves, 2003b, p. 183).

6 O colóquio internacional "O Futuro dos Museus Etnográficos”, realizado em 2013 no Pitt-Rivers Museum (Oxford, Inglaterra), mostra a atualidade da reflexão crítica que vem sendo realizada mundialmente sobre as narrativas expográficas dos chamados museus etnográficos (Lima Filho; Athias, 2016, p. 71).

7 Um exemplo desse tipo de museologia colaborativa, que vem crescendo em escala global, pode ser visto no dossiê "Patrimônios indígenas e coleções etnográficas", organizado por Françozo e Van Broekhoven (2017). O dossiê apresenta os resultados de uma oficina realizada no Instituto Holandês de Estudos Avançados (NIAS-KNAW) com representantes dos povos indígenas Ka'apor e Kayapó, ao lado de curadores e especialistas de universidades e museus europeus e brasileiros. O dossiê reitera os limites, as dificuldades, as possibilidades e os avanços dessa experiência de museologia colaborativa. 
No contexto contemporâneo, quando as políticas de identidade ganham lugar de destaque, as atenções se voltam de maneira especial para a função dos museus no que toca às demandas de representação cultural. Povos indígenas vêm-se apropriando dos museus para o fortalecimento de sua memória. Nos museus indígenas, representações estereotipadas e anacrônicas podem ser substituídas pela autorrepresentação e os acervos podem ser utilizados para a produção de conhecimento sobre si próprios, respeitando a diversidade epistemológica. Os museus indígenas servem ainda, fundamentalmente, para propagar o ativismo político:

Apesar das boas intenções das parcerias colaborativas, estes objetivos parecem ser mais viáveis nos museus indígenas - espaços onde haveria mais possibilidades de introduzir, com maior ênfase, a história e a política, questionando e desafiando as apresentações insuficientes e/ou estetizadas e/ou generalizantes e/ou ambíguas dos museus dominantes. (Roca, 2015, p. 129).

Nos museus criados e administrados por indígenas, são estes que assumem a tarefa e o poder de classificar e nomear, construindo narrativas de autorrepresentação, alinhadas às suas epistemologias e às suas lutas políticas. Quando os indígenas assumem o protagonismo nas experiências museológicas, seus museus passam a estar direcionados, sobretudo, para eles próprios, "visando que os membros dos seus povos aprendam sobre suas histórias e culturas, e sintam orgulho delas" (Roca, 2015, p. 133). Os museus, como uma prática adotada e adaptada pelos indígenas, tornam-se espaços educativos para a comunidade local e - por que não? - para a sociedade em geral. Conforme argumenta Hoerig (2010), esse é um modelo que possibilita maior reciprocidade, em que tanto as comunidades indígenas quanto as não indígenas podem se beneficiar com as exposições.

No Brasil, o Museu Magüta é um significativo exemplo desse processo. Localizado em Benjamin Constant (AM), o museu foi destinado à promoção e à preservação da cultura dos índios ticuna. A organização do Museu Magüta, com participação ativa dos indígenas, ocorreu exatamente no período em que os Ticuna encontravam-se mobilizados na luta por seu território. E o museu foi, nesse contexto, um importante auxílio no fortalecimento da identidade do grupo e no reconhecimento da legitimidade de suas demandas. Nas palavras de 
Freire (2003, p. 219), tal experiência revela a descoberta, pelas lideranças indígenas, do grande potencial dos museus. ${ }^{8}$

Outro caso exemplar, no qual me detenho, é o centro cultural Anishinabe, criado pelos próprios indígenas na reserva do grupo Saginaw Chippewa, nos Estados Unidos da América. Não se trata de um caso isolado, uma vez que os chamados "museus tribais" vêm-se multiplicando na América do Norte. ${ }^{9}$ Esse fenômeno está diretamente relacionado às mudanças sociopolíticas nos Estados Unidos e no Canadá no que tange aos direitos dos povos indígenas. Os museus conformam um elemento a mais na luta levada a cabo pelos indígenas visando a soberania, que inclui o direito sobre suas próprias histórias e tradições culturais. Com origens nas décadas de 1960 e 1970, em meio às demandas políticas dos movimentos Black Power e Red Power, um processo amplo de renovação e descolonização dos museus tem ocorrido nos Estados Unidos (Françozo; Van Broekhoven, 2017, p. 709). Como indica Roca (2015, p. 119), a apropriação do espaço museológico pelos indígenas nos Estados Unidos ganhou ainda mais força com a promulgação, em 1990, da "Lei de Proteção e Repatriação de Túmulos de Nativos Americanos" (Native American Graves Protection and Repatriation Act - NAGPRA). O NAGPRA teria estimulado, entre os indígenas, a vontade de administrar suas próprias coleções e de reescrever suas próprias histórias, numa revisão das narrativas hegemônicas. Embora seja necessário ter em mente esse contexto geral, é preciso notar também que o conceito ocidental de museu tem sido apropriado de diferentes maneiras pelos indígenas norte-americanos, gerando situações ímpares, que merecem ser analisadas individualmente. Aqui concentro a atenção na experiência do Ziibiwing Center, instituição criada pelos Anishinabe. ${ }^{10}$

8 Além do Museu Magüta, Freire (2003) analisa outras cinco experiências museológicas que marcam a descoberta do museu pelos índios no Brasil. São elas: a Embaixada dos Povos da Floresta, o Museu Aberto do Descobrimento, o Museu do Índio de Brasília e duas grandes exposições etnográficas organizadas pelo Museu Amazônico da Universidade do Amazonas e pelo Museu Paraense Emílio Goeldi.

9 Segundo Hoerig (2010, p. 72), até 2010 havia 236 museus indígenas nos Estados Unidos.

10 Roca (2015) analisa outras experiências museológicas nos Estados Unidos da América e no Canadá, nomeadamente: o National Museum of the American Indian - Smithsonian Institution, em Washington, DC; o Museum of Anthropology of the University of British Columbia, em Vancouver; o Canadian Museum of Civilization, em Ottawa; o Makah Cultural and Research Center, em Neah Bay, estado de Washington; o A:shiwi A:wan Museum and Heritage Center, no Novo México; e o U'mista Cultural Centre, em Alert Bay, no Canadá. 


\section{Os Anishinabe}

A Nação Anishinabe tem ocupado, historicamente, parte significativa da região dos Grandes Lagos, na América do Norte (Figura 1). Antes do contato com os europeus, habitaram amplas porções de terra em torno dos lagos Superior, Michigan, Huron, Erie e Ontario. Como outros tantos grupos indígenas situados originalmente mais a leste da América, sofreram grandes deslocamentos à medida que os europeus avançavam no processo de conquista. Contudo, ainda hoje, os Anishinabe têm importante presença na região, tanto em território canadense quanto em terras estadunidenses.

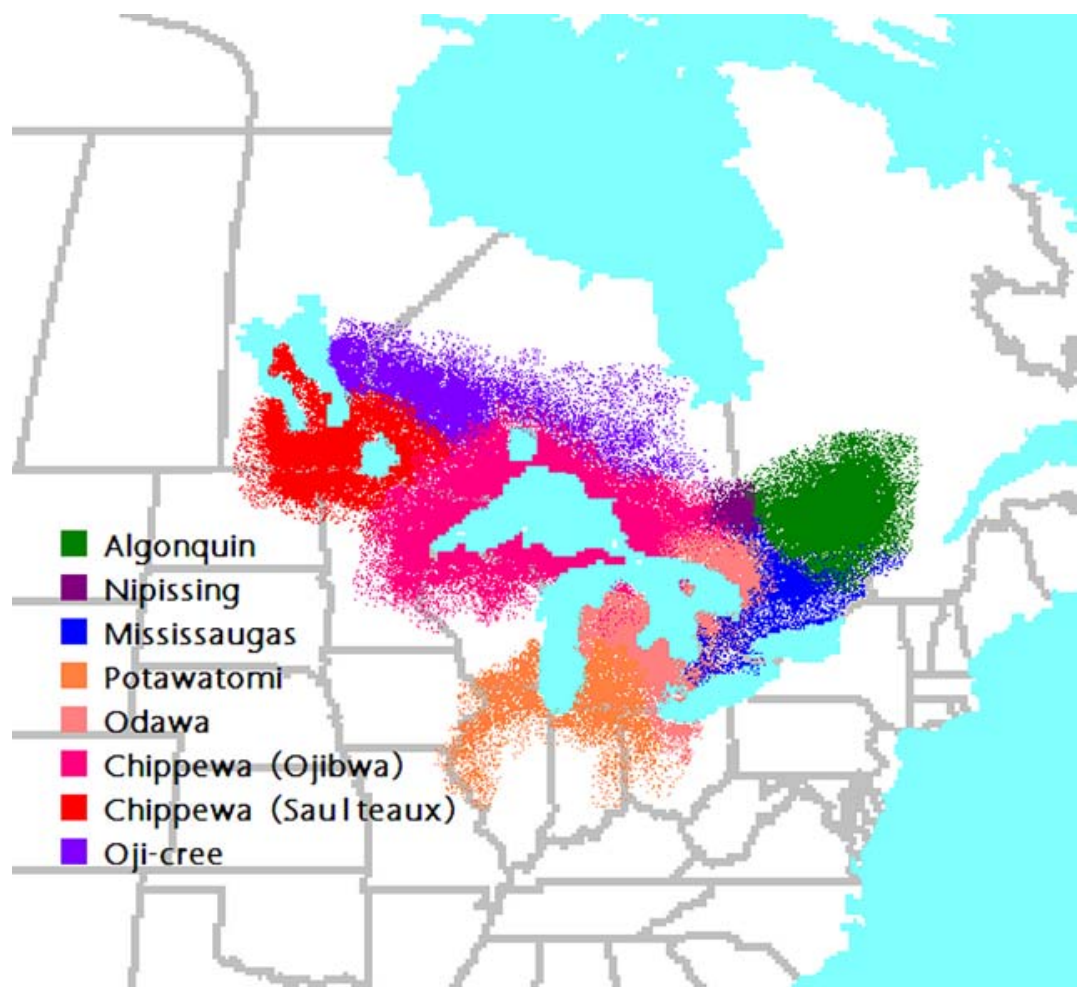

Figura 1. Presença anishinabe na América do Norte

(fonte: https://commons.wikimedia.org/wiki/File:Anishinaabe-Anishinini_Map.PNG; autor: Charles Jirô Lippert; domínio público). 
Os Anishinabe pertencem à família linguística algonquina. Encontram-se subdivididos em três grupos: Ojibwa (Chippewa), Odawa (Ottawa) e Ishkodaywatomi (Potawatomi). Entre eles, foram estabelecidas alianças militares ao longo de uma história marcada por conflitos interétnicos com outros povos indígenas. Mas, sobretudo, é a cosmologia anishinabe que fortalece a relação entre os três grupos, fazendo deles, juntos, a Confederação dos Três Fogos. Segundo a cosmologia anishinabe, cada um dos três grupos tomou para si uma tarefa fundamental para a sobrevivência da nação. Os Potawatomi responsabilizaram-se pela guarda do Fogo Sagrado. Aos Ottawa foi imputada a responsabilidade de fornecer comida para toda a nação, assumindo a maior parte das expedições de caça e troca. Por sua vez, os Ojibwa assumiram o posto de guardiões da fé (Benton-Banai, 1988, p. 98).

Outras duas grandes tradições culturais floresceram, de maneira relativamente independente, na área etnográfica dos Grandes Lagos. À altura dos primeiros contatos com os europeus, estava presente, mais a leste, o complexo cultural neutral, huron e iroquês, localizado, predominantemente, às margens do Lago Erie e na região ao redor de Georgian Bay. A oeste, desenvolveu-se a tradição oneota, usualmente relacionada à família linguística sioux (Cleland, 1992, p. 27). Estes dois grandes complexos culturais apresentavam diferenças substanciais com relação aos predecessores dos atuais grupos algonquinos (Ojibwa, Ottawa e Potawatomi, em especial).

Até chegar, de fato, à região dos Grandes Lagos, os ancestrais anishinabe participaram de um longo processo migratório. A nação, original da costa leste da América do Norte, junto ao Atlântico (na altura da foz do rio St. Lawrence), seguiu rumo ao oeste em um movimento de caráter messiânico. Supõe-se que a migração tenha tido início por volta de 900 d.C., quando os Anishinabe partiram para a realização de uma profecia. Pormenores dessa trajetória são narrados hoje pelos grupos que compõem a Nação Anishinabe. Por meio de mitos e representações visuais, como mapas e diagramas, os indígenas constroem uma versão mito-histórica desse fenômeno migratório, que vem ao encontro das descobertas alcançadas pelos arqueólogos.

A história dessa nação, desde a experiência migratória e o contato com os europeus até os acontecimentos mais recentes, é hoje contada pelos próprios membros do grupo no Ziibiwing Center, em uma exposição de longa duração, intitulada Diba Jimooyung ("Contando nossa história"). 


\section{O Ziibiwing Center}

No estado de Michigan, há onze "tribos"11 reconhecidas pelo governo federal. A organização política desses grupos segue curiosa tendência, observável no conjunto dos povos indígenas que habitam os Estados Unidos. Em resposta a um insistente esforço do governo federal em "democratizar" os povos indígenas, eles têm adotado sistemas de governo similares ao próprio sistema norte-americano, com o critério da maioria de votos nas decisões e nas eleições para cargos e conselhos (Melatti, 2007). ${ }^{12}$ Os termos "tribo" e "bando", há muito tempo abandonados pelos antropólogos, têm sido forçosamente adotados pelos próprios grupos indígenas no processo de reconhecimento de sua identidade e soberania frente ao governo e à sociedade nacional como um todo.

Outra característica importante das reservas indígenas nos Estados Unidos é que elas estão sob jurisdição federal, obedecendo a leis federais, e não estaduais. Não são coletados impostos estaduais, por exemplo, e o governo tribal tem autonomia no que tange a uma série de questões, como a autorização para atividades de caça e pesca. Situação similar ocorre no âmbito da legislação sobre jogos, que recebem regulamentação específica nas reservas, seguindo não as rígidas leis estaduais, mas as determinações do Indian Gaming Regulatory Act (Cleland, 1992, p. 291-292). A lei, aprovada pelo governo federal no ano de 1988, fornece as bases normativas para a operação de jogos em tribos indígenas, de tal forma que a prática seja liberada no intuito exclusivo de promover o desenvolvimento econômico da tribo e sua autossuficiência. Decorre daí que muitas reservas (quase todas, no caso do estado de Michigan) encontram no jogo sua principal fonte de arrecadação de verbas.

O grupo enfocado neste ensaio, Saginaw Chippewa Tribe of Michigan, segue de perto esse padrão. A reserva conta, dentro de seus limites, com um imponente cassino, em torno do qual gira parte considerável da economia local. ${ }^{13}$ Hoje, a

11 Categoria utilizada localmente.

12 Através do Indian Reorganization Act, de 1934, a legislação dos Estados Unidos exige que as tribos adotem uma constituição e que elejam um conselho tribal para serem consideradas aptas ao reconhecimento do governo federal.

13 Os dados apresentados por Cleland (1992, p. 291) indicam uma população de apenas 1702 membros, descendentes dos bandos Black River, Swan Creek e Saginaw, vivendo em uma reserva de não mais que 1400 acres de terra (567 hectares). 
tribo Saginaw Chippewa usufrui dos fundos gerados pelo cassino, capazes de manter invejável infraestrutura, com seu próprio tribunal, corpo policial e escolas, inclusive uma instituição de ensino superior (Saginaw Chippewa Tribal College), além de uma associação atlética, clínica médica, academia de ginástica e um parque para lazer, tudo dentro dos limites da reserva. O cassino e hotel Soaring Eagle, frequentado especialmente por não indígenas, é o maior empregador no condado Isabella, onde se localiza a reserva. Promove uma série de eventos de entretenimento ao longo do ano. Além de atividades em torno do bingo, jogos de cartas e máquinas caça-níqueis, organiza espetáculos musicais com artistas de renome. O hotel é decorado com valiosa arte indígena e oferece a seus hóspedes luxo e conforto, especialmente nos serviços de gastronomia e no spa. Trata-se de um conjunto de atividades que movimenta significativa quantia de dinheiro.

A criação do centro cultural aqui abordado, o Ziibiwing Center, seguiu-se a esse momento de grande fortalecimento econômico da tribo Saginaw Chippewa. Uma das características mais marcantes do Ziibiwing Center é sua estrutura física, capaz de refletir o poder aquisitivo de um dos grupos indígenas mais ricos da América do Norte (Figura 2). O edifício de aproximadamente $3000 \mathrm{~m}^{2}$ é resultado de um investimento de dez milhões de dólares (Hoffman, 2004).

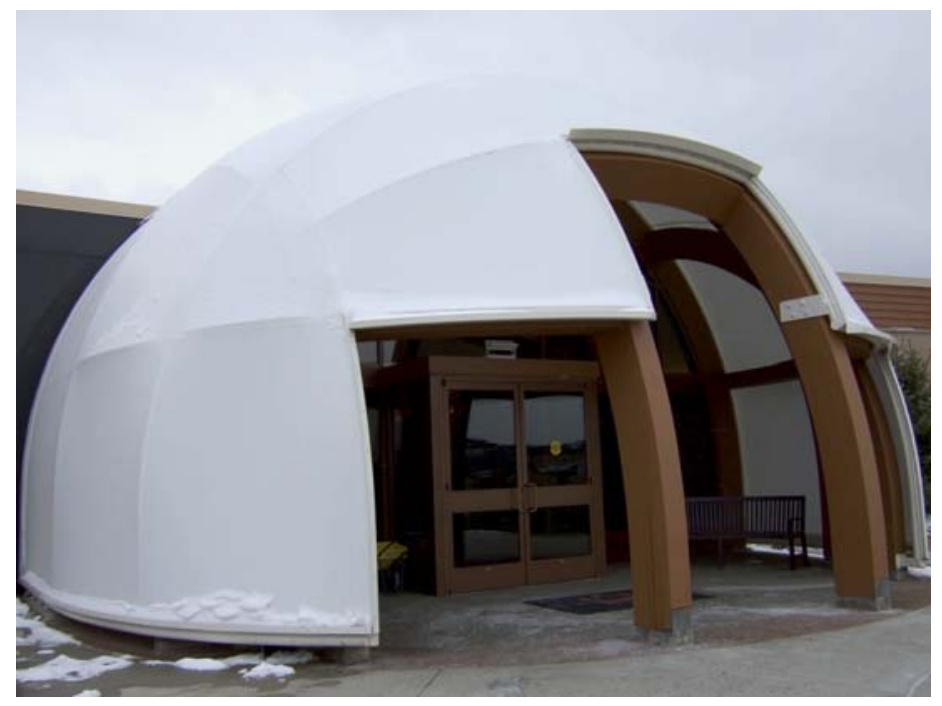

Figura 2. Entrada principal do Ziibiwing Center (foto: acervo pessoal da autora). 
A instituição - Ziibiwing Center of Anishinabe Culture \& Lifeways - foi fundada em 2004. Comporta uma exposição de longa duração, uma exposição temporária, um centro de pesquisa, um café e uma loja, onde são vendidos livros, filmes com atores indígenas, joias, miçangas, instrumentos musicais, roupas, quadros e souvenires diversos.

O Ziibiwing Center foi planejado com intuito educativo e pensado como uma forma de reivindicar a cultura, a herança e a história da Nação Anishinabe, compartilhando esses saberes com as populações não indígenas. A instituição descreve assim sua missão:

O Ziibiwing Center é um tesouro singular criado para proporcionar uma experiência educacional enriquecida, diversificada e culturalmente relevante. Ele fortalece a crença da sociedade em que a cultura, a diversidade e o espírito da Tribo Indígena Chippewa de Michigan e de outros Anishinabek dos Grandes Lagos devem ser reconhecidos, perpetuados, compartilhados e apoiados. ${ }^{14}$ (tradução minha).

Vale destacar a intenção dos fundadores da instituição de deslocá-la de uma trajetória museológica tradicional ao atribuir-lhe a classificação de "centro cultural", em lugar de "museu". ${ }^{15}$ Outra faceta importante do Ziibiwing Center é sua atuação como uma "secretaria de preservação histórica", localizando restos mortais de ancestrais e seus objetos funerários para repatriação e sepultamento.

A exposição de longa duração foi organizada com participação direta dos membros da tribo Saginaw Chippewa. Embora tenham sido contratados profissionais de fora do grupo para auxiliar na elaboração da exposição, o resultado final foi um produto das recomendações da comunidade tribal, reunida em workshops para discussão atenta sobre o projeto. Em uma inversão da colaboração usual,

14 Disponível em http://www.sagchip.org/ziibiwing/index.htm (acesso em 20/01/2018).

15 Este não é um caso único no que se refere à resistência à terminologia museológica. O U'mista Cultural Centre em Alert Bay (Canadá), abordado por Roca (2015), é uma referência entre os museus indígenas que igualmente adotou a categoria de "centro cultural". Segundo um dos Kwakiutl fundadores desse centro, "os índios não vão aos museus" (Cranmer Webster, 1990 apud Roca, 2015, p. 128). 
quando indígenas são convidados a representar seus respectivos povos na reflexão sobre os processos de construção dos acervos museais, aqui foi a própria comunidade indígena que financiou e determinou os objetivos da exposição e estabeleceu o que gostaria que o público sentisse e entendesse sobre a história Anishinabe ao visitar a exposição. Os indígenas participaram ainda de todas as etapas do processo de seleção dos artefatos, imagens e textos expostos. ${ }^{16}$ Até hoje, o Conselho Administrativo desse centro cultural está submetido ao Conselho Tribal e à Administração Tribal.

\section{A exposição de longa duração e a construção de um discurso}

Em visita ao Ziibiwing Center, pude observar não apenas o esplendor das técnicas de exposição, mas também, e principalmente, a particularidade da história narrada através daquelas peças, dos sons, das luzes, dos textos escritos, dos vídeos exibidos. A exposição, que leva em torno de uma hora para ser percorrida pelo visitante, segue uma lógica espacial própria, formando dois círculos que se combinam, subdivididos em 15 áreas, em um ambiente de mais de $800 \mathrm{~m}^{2}$ (Figura 3). As áreas são assim denominadas: 1) Petróglifos; 2) Introdução à História da Criação Anishinabe e ao Cinema da Criação; 3) Casa de Ensino; 4) De Onde Viemos; 5) Casa de Inverno; 6) Contato e Coexistência; 7) Efeitos da Colonização; 8) Mudanças Ambientais; 9) Memórias do Sangue; 10) Língua; 11) Forças Anishinabe; 12) Introdução à Soberania; 13) Cinema da Identidade; 14) Espírito de Soberania; e 15) Continuando a Jornada. A ordem cronológica da narrativa aí construída é preponderante.

16 Agradeço a William Johnson, funcionário do Ziibiwing Center, pelas informações referentes ao planejamento e à organização da exposição permanente. 


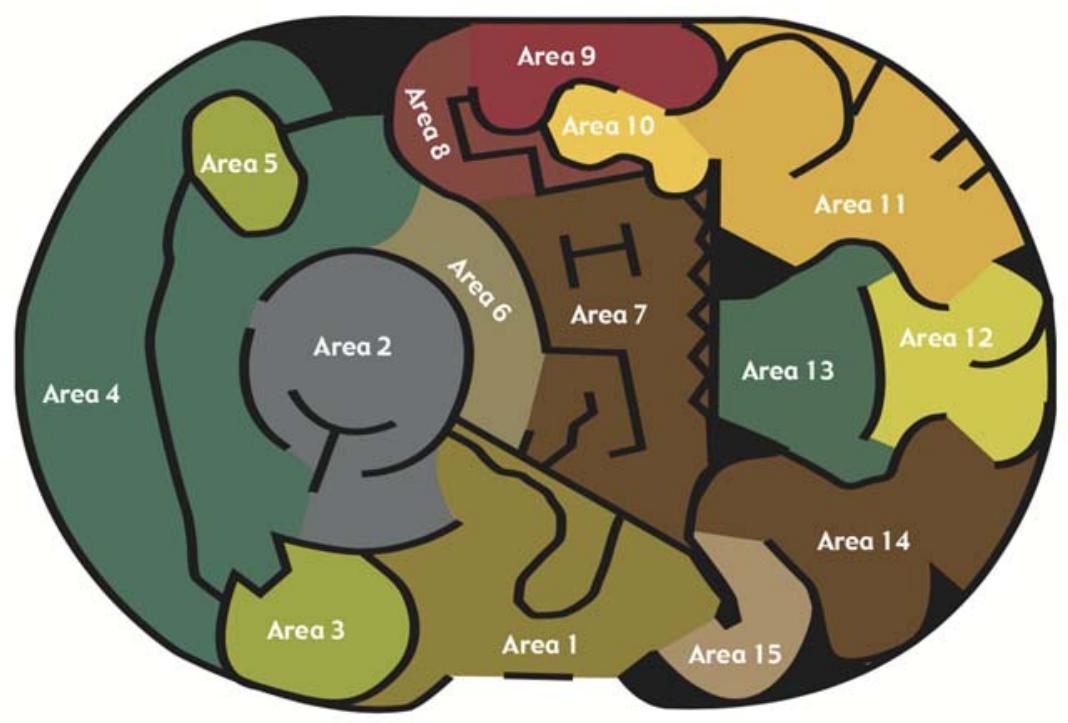

Figura 3. Organização espacial da exposição permanente (fonte: brochura fornecida aos visitantes à entrada da exposição).

Logo no início da exposição (área 2), o visitante é apresentado ao mito de origem Anishinabe, reproduzido em um pequeno cinema, cuja estrutura também explora as formas circulares, simulando o modelo de residência tradicional do grupo. À entrada do cinema, um aviso prepara o público: "Todas as histórias de criação são verdadeiras." O filme, com dez minutos de duração, foi produzido com técnicas de animação, baseadas no padrão estético das artes gráficas do próprio grupo. Luzes e efeitos sonoros combinam-se na produção de um ambiente particular, que lembra um planetário, coberto de estrelas. ${ }^{17}$ Digno de nota é o fato de que este "Cinema da Criação" já recebeu importante premiação (Gold Muse Award 2005), atribuída pelo American Association of Museums,

17 Parte da animação exibida no Cinema da Criação pode ser vista no website da produtora Sweet \& Fizzy, em http://www.sweetandfizzy.com/demo-reel/ (trecho: 2'08" a 2'50") (acesso em 20/01/2018). 
Media and Technology Committee, em reconhecimento pelo alto padrão de qualidade no uso da tecnologia para educação nas áreas de história e cultura. ${ }^{18}$

Acrescidos à exibição do filme, textos escritos e registros sonoros combinam-se para recontar a criação do primeiro homem e as sete profecias recebidas pelos Anishinabe do criador. As profecias têm sido narradas pelos Anishinabe ao longo de várias gerações e, acreditam, estarão sempre guiando o futuro desse povo. Segundo a narrativa, elas foram transmitidas aos Anishinabe por sete profetas, quando o grupo ainda habitava a costa leste da América do Norte. Cada uma das profecias foi denominada um "fogo", e cada fogo referia-se a um tempo particular no porvir.

À medida que avançamos na exposição, luzes se acendem, guiando os visitantes, passo a passo, pelas sete profecias. É na área 3 - a Casa de Ensino - que a primeira profecia é apresentada. Ela anuncia o tempo em que a nação Anishinabe iniciaria sua migração rumo ao oeste. O grupo é instruído a dar início à "Grande Caminhada". Deveriam seguir em busca de uma ilha em formato de tartaruga. Aqueles que ficassem para trás, sem abandonar sua terra original, seriam destruídos.

A segunda profecia anuncia um dilúvio, momento em que o grupo perde a direção e se enfraquece espiritualmente. Já a terceira profecia anuncia um tempo de esperança. Indica que os Anishinabe reencontrarão o caminho para a terra escolhida, a oeste.

Enquanto as profecias vão sendo apresentadas, o visitante pode observar também aspectos da vida dos ancestrais anishinabe, em reproduções das habitações (Figura 4) e do cotidiano do grupo. A área 4 (De Onde Viemos) traz bonecos adornados que exibem o vestuário e atividades como a produção de alimentos (Figura 5). Em seguida, a área 5 (Casa de Inverno) aborda a separação sazonal do grupo em pequenas unidades familiares durante os meses mais frios, a fim de minimizar a competição durante a caça.

18 Outras premiações recebidas pelo Ziibiwing Center foram: Michigan Cultural Alliance “Museum Award” (2006) e Harvard University “Honoring Nations” Award (2008). 


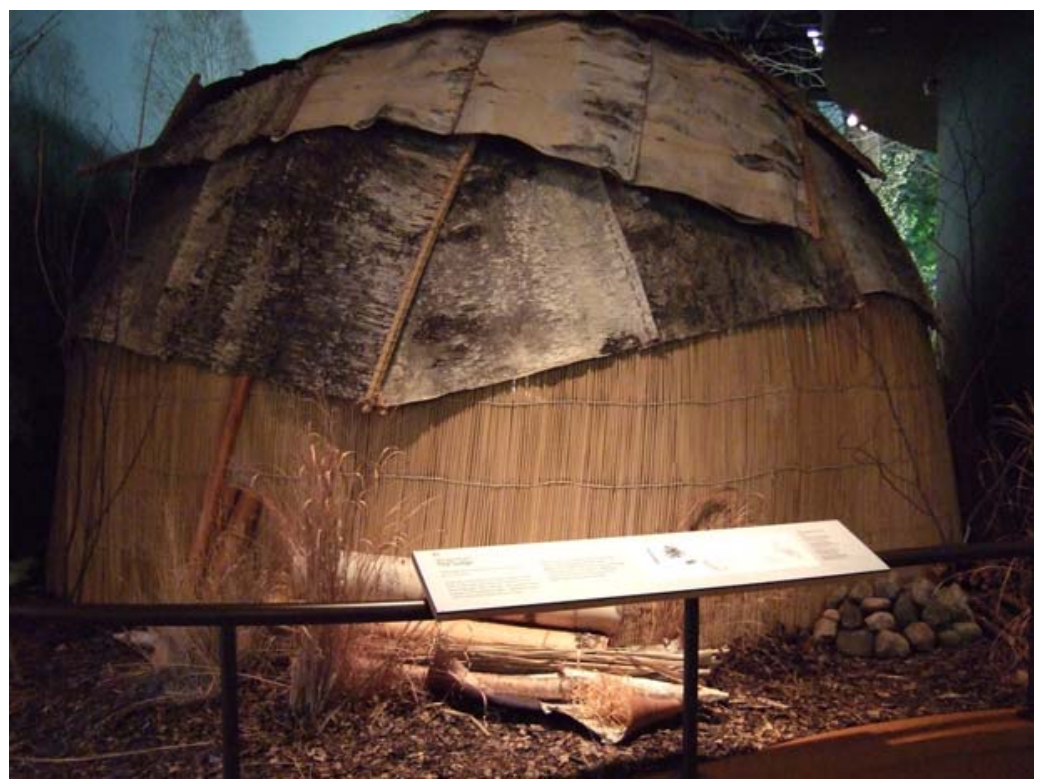

Figura 4. Réplica de residência tradicional (foto: acervo pessoal da autora).

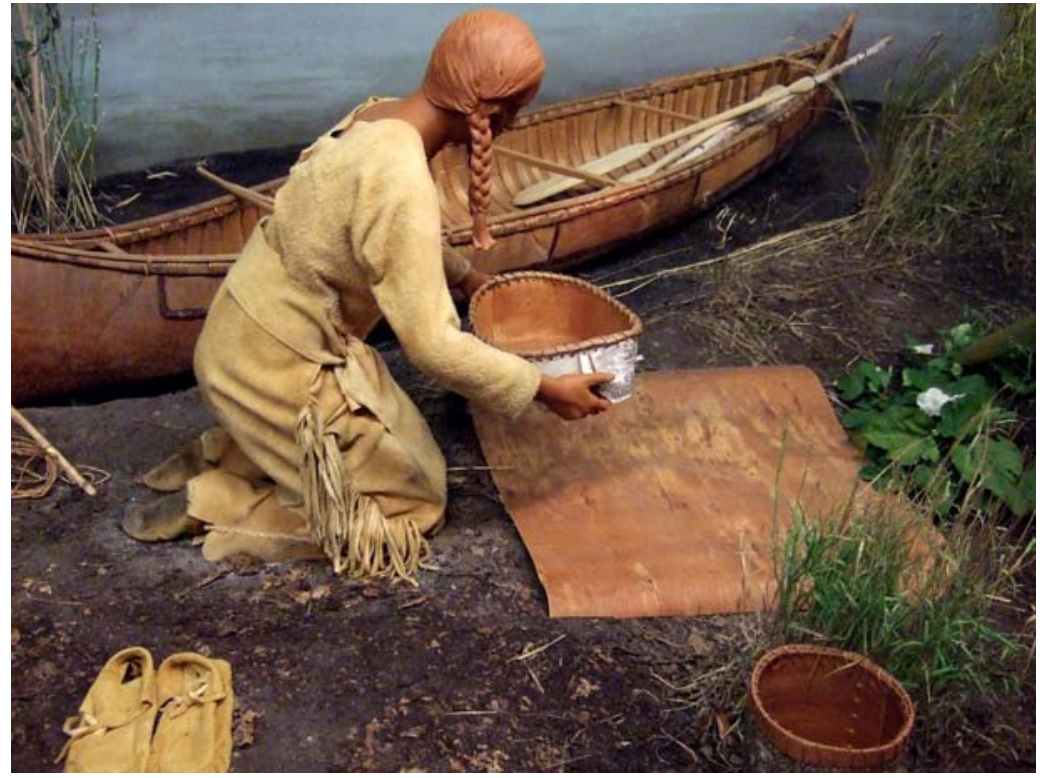

Figura 5. O cotidiano dos ancestrais anishinabe (foto: acervo pessoal da autora). 
A quarta profecia (ou "fogo") foi oferecida por dois profetas, vindos como um só. Eles anunciaram a chegada da "Raça de Pele Clara", dizendo:

Vocês saberão o futuro do nosso povo conforme a face usada pela Raça de Pele Clara. Se eles chegarem usando a face da fraternidade, então virá um tempo de maravilhosas mudanças para as gerações que virão. Eles trarão novos conhecimentos e artigos que podem ser reunidos aos conhecimentos desta terra. Dessa forma, duas nações se juntarão para formar uma nação vasta e poderosa. [...] Fique atento se a Raça de Pele Clara vier usando a face da morte. Vocês precisam ter cuidado porque a face da fraternidade e a face da morte são muito parecidas. Se eles vierem carregando uma arma... cuidado. [...] O coração deles pode estar cheio de ganância pelas riquezas desta terra. Se eles são, realmente, seus irmãos, deixe-os provar. Não os aceite com total confiança. (Exposição permanente do Ziibiwing Center, tradução minha).

Essa profecia é apresentada na área 6 (Contato e Coexistência), que narra a chegada dos franceses em território Anishinabe, enquanto apresenta mapas dos pontos de contato. Textos escritos explicam aos visitantes da exposição que os franceses aprenderam a língua e os costumes locais, ao mesmo tempo em que trouxeram objetos que tornaram a vida dos Anishinabe mais fácil. Era um tempo de convívio harmônico, fundado no interesse mútuo pelo comércio.

A seguir, a exposição começa a trazer outras narrativas do contato. A quinta profecia traz o anúncio de um tempo de muita luta para os povos indígenas, quando a "Raça de Pele Clara" apresentará falsas promessas, propondo uma nova forma de vida. A área 7 (Efeitos da Colonização) trata de doenças devastadoras, políticas governamentais prejudiciais, destruição das economias de subsistência tradicionais e perseguição religiosa. Essa parte da exposição traz em destaque informações sobre a "Era dos Tratados", quando o governo dos Estados Unidos, no período que seguiu à independência, assinou tratados com centenas de nações indígenas, trocando terras por pagamentos e direitos de acesso.

Há a exibição de uma reprodução da obra de Howard Chandler Christy (The signing of the Treaty of Greene Ville, 1795), produzida em 1945 e hoje abrigada em um edifício do governo do estado de Ohio. Ainda, as paredes exibem fotografias de antigas lideranças indígenas (Figura 6). Os textos escritos abordam criticamente os projetos civilizatórios aos quais os indígenas estiveram submetidos, 
como as escolas para crianças indígenas e as atividades missionárias. São apresentadas fotografias relativas à Mt. Pleasant Indian Industrial School, que funcionou entre 1893 e 1934, com uma média de 300 alunos por ano. A escola foi resultado de um dos tratados assinados pelos Anishinabe de Michigan com o congresso americano.

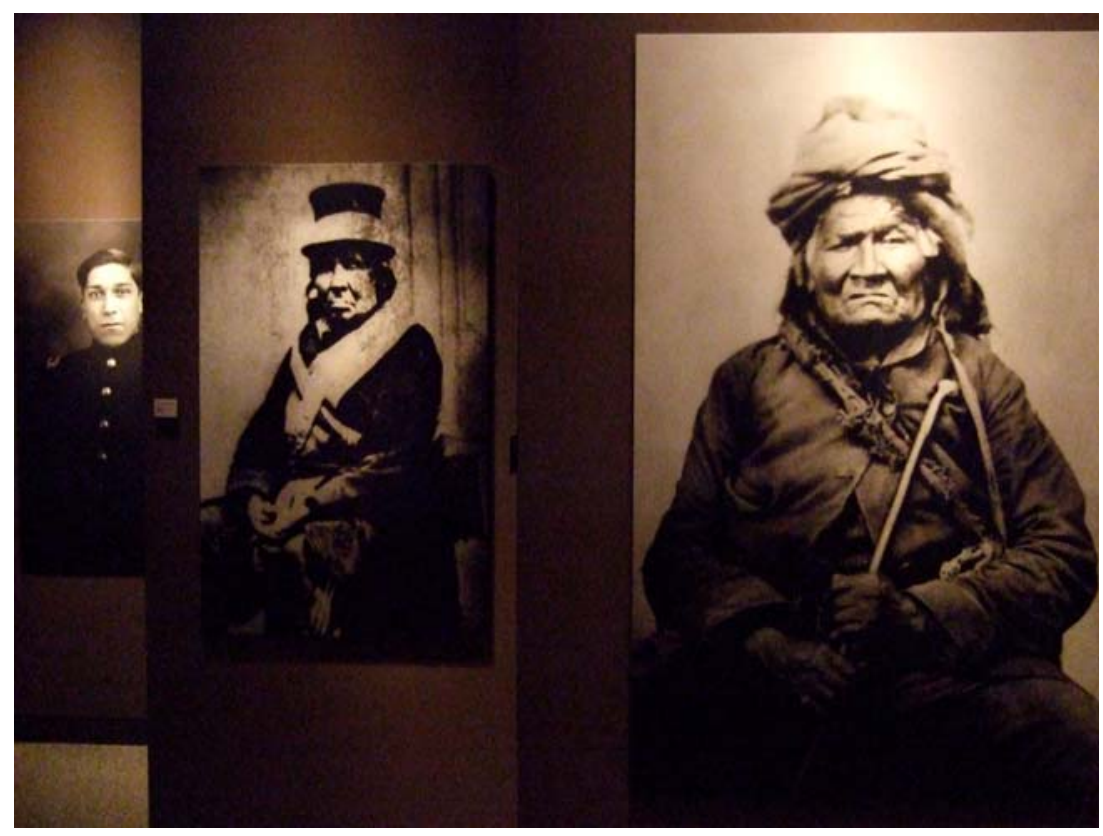

Figura 6. Memória de antigas lideranças indígenas (foto: acervo pessoal da autora).

A sexta profecia anuncia um período em que muitos Anishinabe aceitarão as falsas promessas, virando as costas à tradição e afastando seus filhos dos ensinamentos dos mais velhos. É a narrativa da perda - da terra, da língua, de todo um estilo de vida. A degradação ambiental é também abordada na área 8.

A sétima profecia traz o anúncio do surgimento de um "Novo Povo", com o retorno às tradições. A exposição, a partir desse ponto, enfatiza o fortalecimento do grupo. Fala da conexão com a língua, as músicas, a espiritualidade e os ensinamentos. São elementos presentes na "memória do sangue", apontada como base 
para a sobrevivência da cultura. Nas áreas 9 a 13, compromisso, resiliência, adaptabilidade e superação tornam-se palavras de destaque. A exposição passa a abordar temas como: o renascimento do orgulho de ser indígena; o revigoramento da ideia de família e de comunidade; a consciência da importância da língua e da manutenção das formas artísticas tradicionais; além do surgimento de novos líderes e de projetos relacionados a crianças e jovens. A importância do cassino para o fortalecimento do grupo é abordada. E objetos do cotidiano são evidenciados - como uma camiseta do movimento indígena americano e um adesivo de carro que afirma "Proud to be Indian" (orgulho de ser indígena).

A exposição se encerra com a área 14, que trata da continuidade da luta pela soberania e pelos direitos dos povos indígenas, e a área 15, que direciona o olhar para o futuro. Uma inscrição na parede interpela o visitante: "Estamos agora no Sétimo Fogo [ou Sétima Profecia] e um caminho precisa ser escolhido. Que caminho você escolherá?" Nesse ponto, paz, compaixão e respeito são apontados como fundamentais para a construção de um futuro melhor.

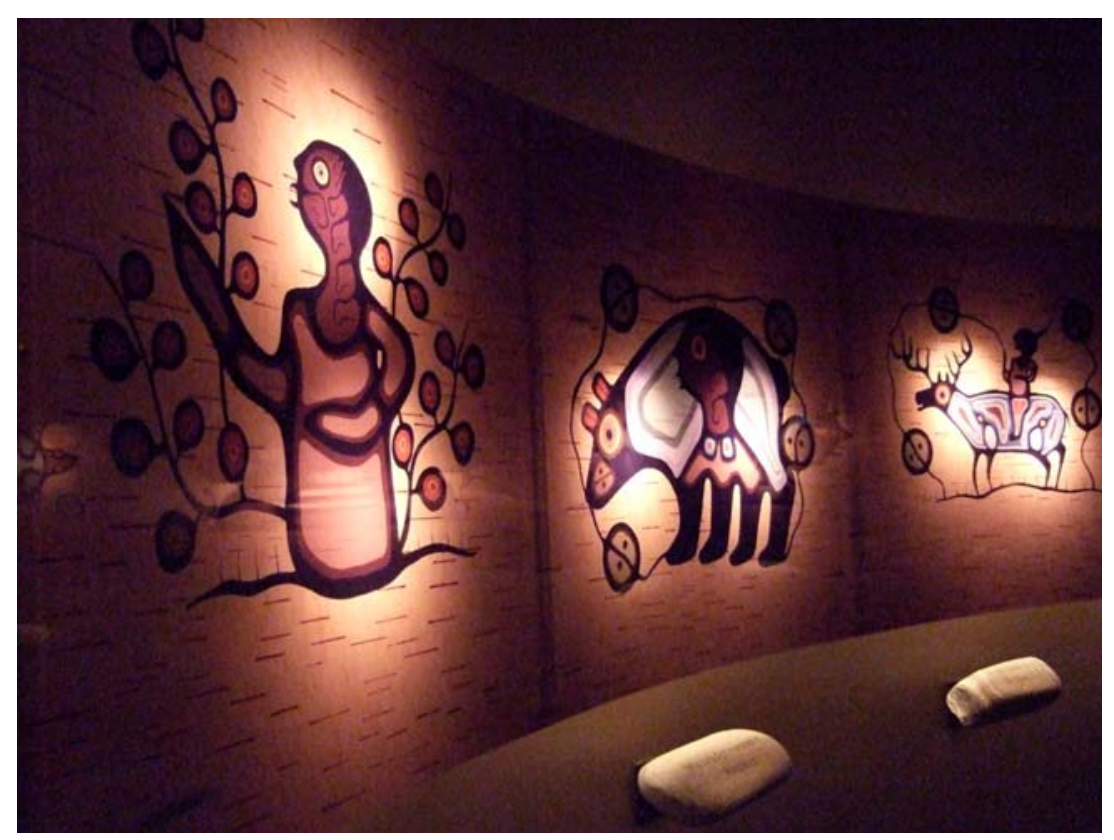

Figura 7. Painel decorativo no Ziibiwing Center (foto: acervo pessoal da autora). 


\section{Mito e história}

Um ponto em especial clama por atenção: trata-se do entrelaçamento entre o tempo histórico e o tempo mítico. A história anishinabe da criação do mundo é o ponto de partida para essa viagem, que tem como mote orientador, ao longo de todo o percurso, as sete profecias recebidas do criador pelos Anishinabe. Paulatinamente e de maneira harmoniosa, essa narrativa mítica vai se combinando à história do contato e dos efeitos da colonização. E o texto que aí se forma ganhe seu ápice, já na sétima profecia, no espaço do que chamam "memória do sangue", isto é, a conexão com os ancestrais, através da língua, das músicas, da espiritualidade e do aprendizado. A identidade anishinabe e a busca contínua pela soberania são a chave que encerra a exibição.

A narrativa apresentada através da exposição permanente do Ziibiwing Center insere-se, portanto, no que chamamos de "cosmologia do contato" (Albert; Ramos, 2002), elaborada através de um registro original. Nessa narrativa museológica, mito e história se articulam, revelando múltiplos aspectos do contato. Trata-se, portanto, de uma síntese em que a história é ordenada culturalmente, ao mesmo tempo em que a cosmologia é ressignificada pela história um processo que tanto tem inspirado a antropologia, a exemplo das discussões realizadas por Marshall Sahlins (1990, 2008).

[...] esse diálogo simbólico da história - diálogo entre as categorias recebidas e os contextos percebidos, entre o sentido cultural e a referência prática - coloca em questão um série inteira de oposições calcificadas, pelas quais habitualmente compreendemos ambas, a história e a ordem cultural. (Sahlins, 1990, p. 181).

O Ziibiwing Center traz uma narrativa potente, capaz de organizar a experiência do presente em termos do passado. Ele constrói uma memória, com fatos, costumes e objetos selecionados, aos quais são atribuídos valores, fundados na cosmologia anishinabe. $\mathrm{E}$ a perspectiva processual da exposição aponta também para o tempo futuro, quando os Anishinabe são encorajados a assumir uma nova posição no cenário sociopolítico local e nacional. Noto ainda que, como parte significativa do público-alvo do museu, os não indígenas são também incluídos nessa narrativa e convidados a seguir o "caminho da compaixão", apresentado pela sétima profecia e fundamentado em 
sete princípios: amor, respeito, bravura, honestidade, humildade, sabedoria e verdade.

O caso aqui apresentado traz uma forma criativa de empoderamento, quando o grupo assume o controle na construção do seu passado, respeitando a historicidade indígena. A construção discursiva do Ziibiwing Center revela um projeto para o fortalecimento da Nação Anishinabe.

O estudo desse caso vem ressaltar uma vez mais a importância do antropólogo na interpretação das interpretações originadas no contexto dos museus. Abertas à reflexão, as narrativas contadas nos museus são mais um caminho para a inesgotável tarefa de compreensão da diversidade cultural.

\section{Referências}

ALBERT, B.; RAMOS, A. R. (org.). Pacificando o branco: cosmologias do contato no norte-amazônico. São Paulo: Editora Unesp, 2002.

BENTON-BANAI, E. The Mishomis book: the voice of the Ojibway. Hayward: Indian Country Communications, 1988.

CLELAND, C. E. Rites of conquest: the history and culture of Michigan's Native Americans. Ann Arbor: The University of Michigan Press, 1992.

CLIFFORD, J. Colecionando arte e cultura. Revista do Patrimônio Histórico e Artístico Nacional, n. 23, p. 69-89, 1994.

DURKHEIM, E.; MAUSS, M. Algumas formas primitivas de classificação. In: RODRIGUES, J. A. (org.). Émile Durkheim: sociologia. São Paulo: Ática, 1981. p. 183-203.

FRANÇOZO, M.; VAN BROEKHOVEN, L. Dossiê "Patrimônio indígena e coleções etnográficas". Boletim do Museu Paraense Emílio Goeldi: Ciências Humanas, Belém, v. 12, n. 3, p. 709-711, 2017.

FREIRE, J. R. B. A descoberta do museu pelos índios. In: ABREU, R.; CHAGAS, M. (org.). Memória e patrimônio: ensaios contemporâneos. Rio de Janeiro: DP\&A, 2003. p. 217-253.

GONÇALVES, J. R. S. A retórica da perda: os discursos do patrimônio cultural no Brasil. Rio de Janeiro: Ed. UFRJ, 1996.

GONÇALVES, J. R. S. O patrimônio como categoria de pensamento. In: ABREU, R.; CHAGAS, M. (org.). Memória e patrimônio: ensaios contemporâneos. Rio de Janeiro: DP\&A, 2003a. p. 25-33. 
GONÇALVES, J. R. S. Os museus e a cidade. In: ABREU, R.; CHAGAS, M. (org.). Memória e patrimônio: ensaios contemporâneos. Rio de Janeiro: DP\&A, 2003b. p. 171-186.

HOERIG, K. A. From third person to first: a call for reciprocity among non-native and native museums. Museum Anthropology, v. 33, n. 1, p. 62-74, 2010.

HOFFMAN, B. T. Telling their story: Saginaw Chippewa's to open cultural center and museum. The Grand Rapids Press, Grand Rapids, p. B5, 19 May 2004.

KOPYTOFF, I. The cultural biography of things: commoditization as process. In: APPADURAI, A. (ed.). The social life of things: commodities in cultural perspective. Cambridge: Cambridge University Press, 1986. p. 64-91.

LIMA FILHO, M.; ATHIAS, R. Dos museus etnográficos às etnografias dos museus: o lugar da antropologia na contemporaneidade. In: RIAL, C.; SCHWADE, E. (org.). Diálogos antropológicos contemporâneos. Rio de Janeiro: Associação Brasileira de Antropologia, 2016. p. 71-83.

LIMA FILHO, M.; ECKERT, C.; BELTRÃO, J. (org.). Antropologia e patrimônio cultural: diálogos e desafios contemporâneos. Blumenau: Nova Letra, 2007.

MALINOWSKI, B. Argonautas do Pacífico Ocidental. São Paulo: Abril Cultural, 1976.

MELATTI, J. C. Índios da América do Norte. 2007. Disponível em: http://www.geocities. com/rainforest/jungle/6885/anorte/anortapr.htm. Acesso em: 9 out. 2007.

MORGAN, L. H. Ancient society or researches in the lines of human progress from savagery, through barbarism to civilization. New York: Henry Holt, 1877.

PRICE, S. Arte primitiva em centros civilizados. Rio de Janeiro: Ed. UFRJ, 2000.

ROCA, A. Museus indígenas na Costa Noroeste do Canadá e nos Estados Unidos: colaboração, colecionamento e autorrepresentação. Revista de Antropologia, São Paulo, v. 58, n. 2, p. 117-142, 2015.

SAHLINS, M. Ilhas de história. Rio de Janeiro: Jorge Zahar, 1990.

SAHLINS, M. Metáforas históricas e realidades míticas: estrutura nos primórdios da história do reino das ilhas Sandwich. Rio de Janeiro: Zahar, 2008.

SANT'ANNA, M. A face imaterial do patrimônio cultural: os novos instrumentos de reconhecimento e valorização. In: ABREU, R.; CHAGAS, M. (org.). Memória e patrimônio: ensaios contemporâneos. Rio de Janeiro: DP\&A, 2003. p. 49-58. 